Int. J. Dev. Biol. 48: 783-791 (2004)

doi: $10.1387 / \mathrm{ijdb} .041903 \mathrm{rl}$

\title{
Pathways regulating lens induction in the mouse
}

\author{
RICHARD A. LANG* \\ Division of Developmental Biology and Department of Ophthalmology. Children's Hospital Research Foundation, Cincinnati, OH, USA
}

\begin{abstract}
For more than a century, the lens has provided a relatively simple structure in which to study developmental mechanisms. Lens induction, where adjacent tissues signal the cell fate changes that result in lens formation, have been of particular interest. Embryological manipulations advancing our understanding have included the Spemann optic rudiment ablation experiments, optic vesicle transplantations as well as more contemporary work employing lineage tracers. All this has revealed that lens induction signaling is a multi-stage process involving multiple tissue interactions. More recently, molecular genetic techniques have been applied to an analysis of lens induction. This has led to the identification of signaling pathways required for lens induction and early lens development. These include the bone morphogenetic protein (Bmp) signaling pathways where Bmp4 and Bmp7 have been implicated. Though no fibroblast growth factor (Fgf) ligand has been implicated at present, the Fgf signaling pathway clearly has an important role. A series of transcription factors involved in early lens development have also been identified. These include Pax6, the Meis transcription factors, Six3, Mab21I1, FoxE3, Prox1 and Sox2. Importantly, analysis has indicated how these elements of the lens induction pathway are related and has defined genetic models to describe the process. It is a future challenge to test existing genetic models and to extend them to incorporate the tissue interactions mediated by the molecules involved. Given the complexity of this and many other developmental processes, a second century of analysis will be welcome.
\end{abstract}

KEY WORDS: development, eye, lens, induction, patterning

\section{Introduction}

With Spemman's optic primordium ablation experiments of 1901, investigation of visual system development has auspicious beginnings. In 1901, the experimental advances of the time were the instruments used to perform embryological manipulations (Weaver and Hogan, 2001). These new instruments allowed tissue ablations and transplantations to define the interactions required for developmental processes. Spemann's work suggested that the optic vesicle was required for development of lens (Spemann, 1901). However, even then, scientific controversies existed; it was only 2 years later that Mencl characterized a mutant salmon in which lenses but not retinas existed (Mencl, 1903). Clearly, this suggested an alternative mechanism of lens development. Since then, many investigators have repeated Spemann's original experiment with varying results. In some cases lenses would form after optic primordium ablation, but in other cases, they would not. These different outcomes probably indicate that different species vary with respect to the timing of lens induction signaling (Servetnick et al., 1996). Even today these experiments form an important backdrop as we try to understand the molecular basis of lens induction.

\section{The embryological origin of the lens}

The lens is derived from the head surface ectoderm of the vertebrate embryo (Fig. 1). The first morphological sign of lens development is the formation of the lens placode. This structure is a thickened region of the head surface ectoderm immediately adjacent to the optic vesicle. The thickening of the lens placode occurs only after the optic vesicle has evaginated from the forebrain and made close contact with the surface ectoderm. The interaction between the optic vesicle and presumptive lens ectoderm is extremely strong and mediated by cytoplasmic extensions between the two tissue layers (McAvoy, 1980). Subsequently there is a coordinated invagination of the lens placode and outer layer of the optic vesicle. This results in the formation of the lens pit and the

Abbreviations used in this paper: bmp, bone morphogenetic protein; EE, ectoderm enhancer region; fgf, fibroblast growth factor; MAPK, MAP kinase.

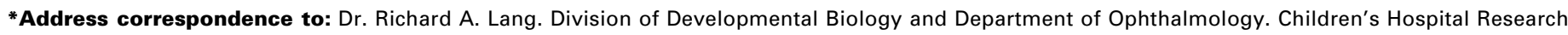
Foundation, 3333 Burnet Avenue, Cincinnati, OH 45229, USA. Fax: +1513-636-4317. e-mail: richard.lang@cchmc.org
} 
optic cup. At this stage, the epithelium of the lens pit closest to the presumptive retina has begun to thicken in the first steps of lens fiber cell differentiation. In addition, the outer layer of the optic cup has folded back against the proximal layer of the optic vesicle to form the adjacent epithelia of the RPE and presumptive retina. Closure of the lens pit at the surface ectoderm results in formation of the lens vesicle. Thickening of the posterior epithelium of the lens vesicle continues as fiber cells differentiate and extend towards the lens epithelium. Clearly, the nature of eye development and, in particular, the close association between the optic vesicle and lens placode has suggested that the optic vesicle might have a critical role in lens induction.

\section{Lens induction is a multi-step process}

In recent times, embryological manipulations have become more sophisticated than the early efforts pioneered by Spemann, and have defined multiple stages in the lens induction process. In particular, the group of Robert Grainger has been able to define at least four stages in lens development (Grainger et al., 1992; Grainger, 1996). These correspond to a period of lens-forming competence (Servetnick and Grainger, 1991) in the mid/late gastrula ectoderm, the acquisition of a lens-forming bias throughout the head ectoderm during neurulation (Grainger et al., 1997), specification of lens cell fate towards the end of neurulation, and differentiation, an aspect of lens development which continues throughout life (Grainger, 1992). While the definition of these stages are described in more detail in another chapter of this volume (Sullivan et al., 2004) it is worth noting that one of the current challenges is to mesh the embryological and molecular genetic definitions of lens induction.

\section{Induction genes become differentiation genes}

While this review emphasizes the early steps in lens development, a large body of experimental work has shown us that many of the developmental pathways critical for lens induction are also critical for later stages of lens development. For example, the Fgf signaling pathway is involved both in inductive signaling (see below) and in the regulation of lens fiber cell differentiation (McAvoy et al., 1999). It is also the case that some transcription factors critical for induction have later roles in differentiation. For example, in the mouse, Pax6 is required for lens induction, but also activates $\alpha B$ crystallin later in lens development (Piatigorsky, 1998). There are also emerging links between induction genes like Pax 6 , transcription factors that are genetically downstream (like the Mafs and Prox 1 ) and the regulation of differentiation genes like the crystallins (Cui et al., 2004). Increasingly therefore, we will have the opportunity to draw a continuous developmental pathway from lens induction to lens function.

\section{Pax6 gene function and regulation}

\section{The Pax6 gene}

The role of the PaxG gene in eye development has been thoroughly investigated over a number of years. Pax6 function is critical for eye development as indicated by the absence of eyes in humans, mice, and flies that carry loss of function mutations in Pax6 (Hill et al., 1991; Glaser et al., 1992; Jordan et al., 1992; Quiring et al., 1994). In vertebrates, Pax6is expressed in a variety of tissues including those that participate in the early phases of eye development. Pax6 is first expressed in the anterior neural plate region that will eventually give rise to the retina (Grindley et al., 1995). Somewhat later, Pax6 is also expressed in a broad region of the head surface ectoderm including the domain that gives rise to the lens. While Pax6 expression is retained in the presumptive retina and the retinal pigmented epithelium as the optic cup develops, the domain of expression in the surface ectoderm becomes restricted to the region of the lens placode and the surface ectoderm immediately surrounding. The expression level of Pax6 increases in the lens placode after close contact with the optic vesicle (Grindley et al., 1995).

Pax6loss-of-function mutations have indicated a critical role for Pax6 in eye development, but in addition, gain-of-function experiments have revealed a remarkable activity in precipitating all of the events required for development of this complex structure. In the first experiment of this type, the Gehring lab demonstrated that misexpression of Drosophila Pax6 (the eyeless gene) could result in the formation of ectopic eyes in multiple locations (Halder et al., 1995). It was shown that this activity was evolutionarily conserved in that both fly and mouse Pax6 could induce ectopic eye formation. This observation was a very powerful argument to suggest that Pax6 occupied the apex of a genetic hierarchy that regulates eye development. In the holometabolous insects, the situation turned out to be slightly more complex in that there are two orthologues of Pax6called eyeless and twin of eyeless (Czerny et al., 1999). These two genes are very closely related and both have the ability to induce ectopic eyes. This has suggested an adaptation in which this group of organisms has duplicated a primordial Pax6 gene and subsequently the two genes have shared duty. A similar situation is also observed in Zebrafish where the duplicated Pax6. 1 and Pax6.2genes are expressed in distinct but overlapping domains (Nornes et al., 1998). In this case, gene duplication is probably a consequence of a much larger partial genome duplication.

Experiments performed in Xenopus leavis have shown that Pax6can induce ectopic eyes in a vertebrate (Chow et al., 1999). Such ectopic eyes form only in the head region, perhaps because there is a restricted domain of eye competent ectoderm in the early Xenopus embryo (Servetnick and Grainger, 1991). Remarkably, ectopic eyes contain all the mature cell types that might be expected, including a selection of appropriately laminated mature retinal neurons, cells of the retinal pigment epithelium as well as those of the lens. The importance of PaxG for the induction of ectopic eye structures has been confirmed by experiments in which different combinations of presumptive eye region genes were misexpressed in Xenopus (Zuber et al., 2003). The ability of Pax6 to induce ectopic eyes in both invertebrates and vertebrates has suggested an evolutionarily conserved function at the apex of a genetic hierarchy controlling eye development (Callaerts et al., 1997).

\section{Pax6 is necessary and sufficient for lens development}

A number of experiments indicate that Pax6 has a critical, autonomous function in development of the lens. In the first of these, tissue recombination experiments were performed using wild type and Pax6 mutant (smalleye) optic vesicle and presumptive lens ectoderm (Fujiwara et al., 1994). It was shown that a combination of wild type optic vesicle and wild type presumptive lens would, as expected, result in lens formation. Similarly, recombining small eye optic vesicle and wild type presumptive lens 
ectoderm also resulted in lens formation. By contrast, recombining wild type optic vesicle with small eye presumptive lens ectoderm failed to give lens formation (Fujiwara et al., 1994). This indicated that lens development required Pax 6 function in the surface ectoderm but not the optic vesicle.

A similar conclusion can be drawn from experiments in which wild type/small eye chimeric mice were generated (Quinn et al., 1996; Collinson et al., 2000). In this circumstance it was observed that small eyemutant cells did not contribute to the lens placode at E9.5 or subsequently to the differentiating lens. The selective aggregation of wild type cells in these chimeric mouse experiments also suggested that Pax6 may have an important role in regulating the adhesive interactions. In the most direct demonstration of the requirement for Pax 6 in lens development a floxed allele of the Pax6gene was conditionally deleted in the lens placode (AsheryPadan et al., 2000). This experimental strategy resulted in a failure of lens development beyond the placode stage. Interestingly, although the retina was misshapen, retinal neuron differentiation and lamination occurred normally.

Gain-of-function experiments have also indicated a central role for Pax6in lens development. If the experimental conditions used to generate ectopic eyes in Xenopus laevis are modified slightly, the result is induction of ectopic lenses at high-frequency (Altmann etal., 1997; Chow etal., 1999). These lenses express lens-specific markers such as $\beta$-crystallin and many have the polarized morphology of a normal lens. In some experiments, remarkably, ectopic lenses are perfect mimics of the endogenous lens in size, morphology and marker expression. Interestingly, lineage tracing studies indicate that these ectopic lenses are a results of the cell autonomous activity of Pax6 (Altmann et al., 1997; Chow et al., 1999). These lenses also form in the absence of any retinal tissue. Combined, gain- and loss-of-function experiments indicate that Pax6 is necessary and, in the context of the Xenopus embryo, sufficient for development of the lens.

\section{Pax6 expression in the lens lineage is controlled by at least two enhancers}

The important role of Pax6in many developmental processes, as well as its complex expression pattern, has motivated analysis of transcriptional regulation. The identification of transcription control elements in Pax 6 has rested on the simple strategy of sequence alignment to identify conserved regions and functional assessment using transgenic reporter constructs (Williams et al., 1998; Kammandel et al., 1999; Xu et al., 1999). If long-range sequence alignments are generated to compare the mouse and human Pax6 genes, it immediately becomes apparent that transcriptional regulation of this gene is complex. Indeed, there are upwards of 40 highly conserved, non-coding sequence regions in Pax6 (see trafac.cchmc.org).

A number of these conserved regions have transcriptional enhancer activity. Approximately $3.5 \mathrm{~kb}$ upstream of the P0 promoter in Pax6, there is a highly conserved region of 340 base pairs that has activity as a lens lineage enhancer (Williams et al., 1998; Kammandel et al., 1999; Xu et al., 1999). This region has been designated $E E$ for ectoderm enhancer. When incorporated into a reporter transgene, the EEgives expression in the developing lens placode and adjacent ectoderm starting at E8.75 in the mouse (Williams et al., 1998; Kammandel et al., 1999; Xu et al., 1999). Subsequently, the $E E$ has activity in the entire lens vesicle but
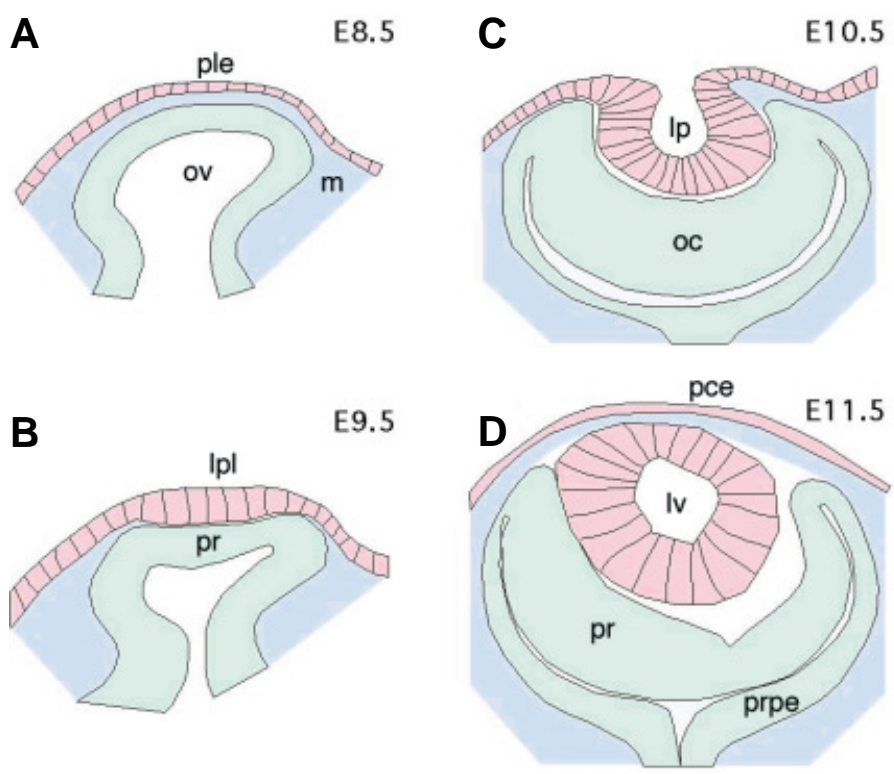

Fig. 1. Morphogenesis of the lens. (A-D) show the stages of lens development in the mouse from E8.5 to E11.5 in daily intervals. The three tissue layers involved in eye development include the surface ectoderm (red) the mesenchyme (blue) and the neuroepithelium of the optic vesicle (green). ple - presumptive lens ectoderm; ov, optic vesicle; $m$, mesenchyme; Ipl, lens placode; $p r$, presumptive retina; Ip, lens pit; oc, optic cup; pce, presumptive corneal ectoderm; Iv, lens vesicle; prpe, presumptive pigmented retinal epithelium.

beyond E11.5 is restricted to the lens epithelium and the epithelia of the lacrimal gland and conjunctiva (Williams et al., 1998; Kammandel et al., 1999; Xu et al., 1999).

The lens lineage enhancer designated SIMO was identified in a more roundabout and interesting way. The van Heyningen group was examining the nature of mutations in Aniridia patients and found a translocation break point situated 3' to the last exon of Pax6 (Kleinjan et al., 2001). Upon further investigation it was shown there were several highly conserved regions of sequence just distal to the translocation breakpoint. Testing of these regions in transgene reporter constructs indicated that one of them, the S/MOelement, had activity in the lens lineage (Kleinjan et al., 2001). While this has not been tested directly, there is a good possibility that SIMO and EE work cooperatively to give the full breadth and level of Pax 6 expression in the presumptive lens region (Treisman and Lang, 2002; Lang and McAvoy, 2003).

\section{There are two phases of Pax6 expression}

Straightforward expression analysis for PaxG in PaxG Sey1Neu homozygotes has indicated that there are two distinct phases of Pax6 expression in the presumptive lens ectoderm of the mouse embryo (Grindley et al., 1995). The Pax6 Sey1Neu allele is a point mutation that still permits gene transcription but does not permit production of functional protein (Grindley et al., 1997). An assessment of Pax6gene expression on this mutant background indicates that expression of Pax6in the head surface ectoderm is retained but that expression in the lens placode (designated Pax6 $6^{\text {placode }}$ ) is lost (Grindley et al., 1995). This indicates that there are two distinct phases of Pax6 expression and that the later 
expression phase (designated Pax6 $6^{\text {pre-placode }}$ ) is dependent on the first phase of expression. These two phases of Pax6 expression constitute the first steps in a genetic pathway describing lens induction in the mouse (Fig. 2). For the reasons indicated above, it is likely that EE and SIMO work in concert to give PaxG placode.

\section{The EE is required for normal development of the lens}

To assess the role of the $E E$ in development of the lens, gene targeting experiments were carried out in which the entire $E E$ was deleted. Homozygous EE deletion mice showed abnormal lens development (Dimanlig et al., 2001). The lens placode was thinner

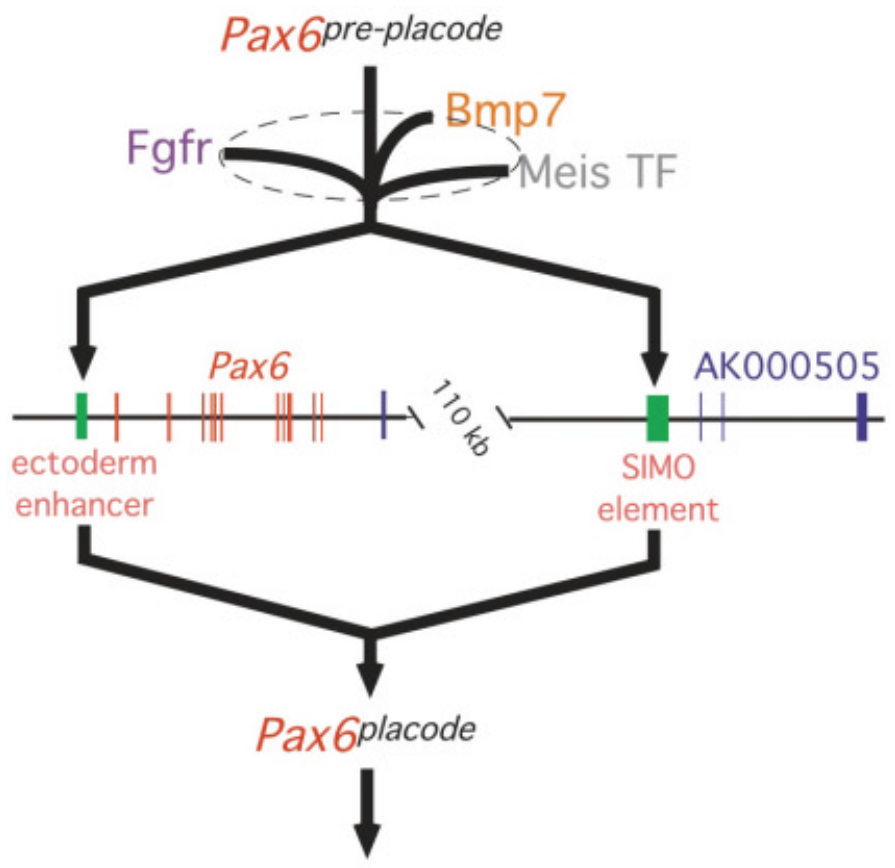

lens development

Fig. 2. Inductive signals regulate Pax6 expression in presumptive lens: a genetic model. The arrows indicate genetic interactions except in the case of the Meis transcription factor-enhancer interactions. At the apex of the hierarchy is the pre-placodal phase of Pax6 expression (Pax6 pre-placode). It is understood that the later phase of Pax 6 expression in the lens placode (Pax6 ${ }^{\text {placode) }}$ is dependent upon earlier activity of Pax6. Pax6 $6^{\text {placode }}$ is apparently regulated by at least two enhancers that are represented by the green vertical bars on the schematic of the Pax6 gene (exons, red vertical bars). One is the so-called ectoderm enhancer and the other the SIMO element that is located in the final intron of the adjacent gene, AK000505, that is transcribed in the opposite direction to Pax6. The Meis transcription factors (Meis TF) are likely to regulate the expression of Pax6 directly by binding to the ectoderm enhancer, and possibly to the SIMO element. Since both placodal Pax6 is reduced in mouse embryos that express a dominant-negative Fgf receptor in the lens lineage it is likely that Pax6 $6^{\text {placode }}$ is genetically downstream of Fgf receptor activity. Given that an even lower level of Pax6 can be recorded in embryos that express the dominant-negative Fgf receptor and have half the normal level of Bmp7, we can suggest that Fgf receptor and Bmp7 signaling cooperate to maintain the placodal phase of Pax6 expression. Previous analysis has shown that the early phase of Pax 6 expression is unaffected in the Bmp7 null mice and thus, FGF and Bmp7 signaling must converge on the pathway downstream of Pax6 $6^{\text {pre-placode. }}$. than normal in mutant mice though this occurred primarily on the nasal side of the structure. Proliferation of presumptive lens cells was also diminished, and, at all stages of development lens structures were smaller than in wild type mice. Consistent with the Peters' anomaly observed in some cases of Pax6heterozygosity, EEhomozygous mice showed a persistent lens stalk and a failure of the lens vesicle to separate from the surface ectoderm. At E9.5 interestingly, Pax6 immunoreactivity could still be detected in the lens placode though it was very much reduced on the nasal side. When combined with reporter construct analysis this suggests that the function of the EE is to promote PaxGexpression primarily on the nasal side of the lens placode. The observation that deletion of the EEdoes not block lens development completely is consistent with the idea that at least one additional enhancer, perhaps the SIMOelement (Kleinjan et al., 2001), is required for the full level of Pax6 expression in the lens placode (Fig. 2). It will be very interesting to compare the phenotype of a SIMOenhancer deletion mouse with that of the EE deletion.

\section{Pax6 lens enhancers may be regulated by Meis transcription factors}

The mammalian Meis family transcription factors have recently been implicated in early development of the lens. The Meis family are TALE-class homeodomain transcription factors (Burglin, 1997) and homologues of the homothoraxgene of Drosophila (Bessa et al., 2002). Meis binding sites have been identified in the ectoderm enhancer of Pax6 (Zhang et al., 2002) and this has suggested that Pax6may be regulated in vivo by this class of transcription factor. The experimental evidence for this suggestion includes, (1) immunoidentification of Meis in a complex with EEprobes in mobility shift assays, (2) transgenic mice showing that the activity of $E E$ is dependent upon Meis binding sites, (3) a genetic interaction between a Meis2transgene and the Pax6 ${ }^{\text {Sey } 1 \text { Neu }}$ allele, and (4) the demonstration that suppressor forms of Meis1 can down-regulate Pax6 expression when transiently expressed in the lens placode (Zhang etal., 2002). More recently, it has been shown that a Meis 1 null mouse has defects in the lens, albeit mild and at a late stage of development (Hisa et al., 2004).

Given the likelihood that at least two enhancers regulate Pax6 expression in the lens placode (Fig. 2), the observed absolute regulation of Pax6by Meis transcription factors (Zhang etal., 2002) requires that they function at both the $E E$ and $S / M O$ elements (Lang and McAvoy, 2003). Identification of Meis binding sites in the $S / M O$ element is of great interest, but further experimentation will be required to precisely define the molecular genetics of this interaction. In particular, it will be very interesting to further analyze the eye phenotypes that arise in mice that are null or conditionally targeted for the combinations of the Meis genes (Zhang et al., 2002). Since expression of the Meis genes is independent of Pax6, they are best incorporated into the model for genetic regulation of lens induction as an input upstream of both the EE and SIMO elements (Fig. 2).

\section{Signaling pathways involved in lens induction}

\section{Bone morphogenetic proteins have important roles in lens development}

The bone-morphogenetic proteins Bmp4 and Bmp7 are both proposed to have important roles in early development of the lens. 
Bmp4 and Bmp7are expressed in the early eye tissues and have overlapping expression patterns (Dudley and Robertson, 1997; Furuta and Hogan, 1998; Wawersik etal., 1999). Bmp7 is expressed in the presumptive lens ectoderm and presumptive RPE as well as the dorsal optic vesicle. Expression of $B m p 7$ in the presumptive lens tissue ceases at about E11.5. Deletion of the $B m p 7$ gene results in variably penetrant eye development defects that range from mild microophthalmia to anophthalmia (Dudley et al., 1995; Luo et al., 1995). The lens placode fails to form in severely affected animals and interestingly, the expression of Pax 6 in the lens placode is lost (Wawersik et al., 1999). This has indicated that $B m p 7$ is genetically upstream of the enhancers that control Pax6 expression in the lens placode (Fig. 2).

While homozygous Bmp4 mutant embryos do not survive past $\mathrm{E} 10.5$, lens formation from the presumptive lens ectoderm of null mutants can be rescued by recombining them with wild type optic vesicles in explant culture (Furuta and Hogan, 1998). This indicates that $B m p 4$ expression in the presumptive lens ectoderm is not required for lens development. Explantation of eye rudiments from Bmp4null mice in the presence of recombinant Bmp4 also resulted in rescue of lens formation (Furuta and Hogan, 1998). However, recombinant Bmp4 was not sufficient to rescue lens formation when presumptive lens ectoderm from null mice was explanted. Combined, these data suggested that Bmp4 had to act in concert with at least one additional signal if lens development was to proceed. Interestingly, the absence of Bmp4 does not affect expression of Pax 6 , but does prevent the normal up-regulation of Sox2, an Sry-related transcription factor normally expressed in both presumptive lens and retina (see below). Combined with other information, this has suggested that Bmp4 and Sox2 may function in a parallel branch of the lens induction pathway (Fig. 2). This also suggests, despite the overlapping expression patterns, that Bmp4 and Bmp7 may have non-redundant functions in early eye development. The demonstration that Pax6 and Sox2 form a complex in the regulation of crystallin genes (Kamachi et al., 2001) has indicated that these pathways may combine to regulate later steps in lens fiber cell differentiation.

\section{FGF receptor signaling is required for lens induction}

The Fgf signaling pathway has important functions at multiple stages of eye development. For example, Fgf signaling is both necessary and sufficient for differentiation of lens fiber cells according to loss- and gain-of-function experiments (McAvoy etal., 1991; McAvoy et al., 1999; Lang and McAvoy, 2003). More recently, we have understood that Fgf receptor activity has an important role to play in the inductive phases of lens development.

Explantation of eye primordia in the presence of a smallmolecule inhibitor of the Fgf receptor kinase activity results in reduced levels of Pax6 in the lens placode (Faber et al., 2001). Given the critical role of Pax6 in lens development, this has suggested that Fgf receptor activity lies upstream and is a lens induction factor. When a dominant-negative FgfR1 is expressed in the presumptive lens, early defects in lens placode formation and lens pit invagination are apparent. Importantly, Pax6 expression levels were reduced (Faber etal., 2001). Genetic evidence of a lens induction function for Fgf receptor activity was pursued by determining whether Bmp7, an established lens inducer (Wawersik et al., 1999) might cooperate with Fgf receptor activity. Indeed, crosses between Bmp7null (Dudley et al., 1995) and Tfr $7 / T f r 7$ mice (transgene homozygotes expressing a dominant-negative FgfR1 in the lens placode) produced compound genotype mice with more severe lens development defects (Faber et al., 2001). In particular, Tfr $7 / T f r 7, B m p 7^{+/}$mice showed a very small lens pit and failed to separate and close the lens vesicle. In addition, Pax6 expression levels in the lens placode were at the lowest levels in Tfr $7 / T f r 7, B m p 7^{+/}$mice, and at intermediate levels (compared with wild-type) in Tfr7/Tfr7mice (Faber et al., 2001). This indicated that Bmp7 and Fgf receptor signaling converge upstream to give a full level of Pax6 expression in the placodal phase (Fig. 2). Though there have been some good candidates (McWhirter et al., 1997; Lovicu and Overbeek, 1998; Vogel-Hopker et al., 2000), the identity of the Fgf receptor ligands required for lens induction remains unclear.

\section{Transcription factors genetically downstream of Pax6}

\section{FoxE3}

Foxe 3 is a transcription factor of the forkheadclass that in mice has a very limited expression range in the developing neural tube and lens (Blixt et al., 2000; Brownell et al., 2000). In humans, mutations in FOXE3 are associated with anterior segment ocular dysgenesis (Semina et al., 2001). In the mouse, expression of FoxE3begins at E8.75 in the presumptive lens ectoderm (Brownell et al., 2000) and represents a sub-domain of Pax6-positive presumptive lens ectoderm. This spatial relationship between FoxE3 and Pax6 expression domains continues through E9.5 (when the lens placode has formed), and E10.5 when the lens pit is invaginating. The $d y s g e n e t i c / e n s(d y /)$ mouse carries mutations in FoxE3(Blixt et al., 2000; Brownell et al., 2000). This results in a failure of lens vesicle closure and separation, as well as reduced proliferation in lens epithelial cells (Blixt et al., 2000; Brownell et al., 2000). The expanded expression domain of Prox 1 in the lens epithelium of the FoxE3 dyldyl mouse (Blixt et al., 2000) has suggested that in this location, FoxE3is a suppressor of Prox1(Fig. 3).

In the Pax6 Sey/Sey background it has been shown that FoxE3 expression is absent, (Brownell et al., 2000) thus suggesting that FoxE3 is genetically downstream of Pax6 (Fig. 3) (Brownell et al., 2000). The phenotypic resemblance of the $d y /$ mouse with those in which the Pax6 upstream ectoderm enhancer had been deleted (Dimanlig et al., 2001) prompted an examination of a possible genetic relationship. In situhybridizations for FoxE3in Pax $\sigma^{\triangle E E / \triangle E E}$ embryos (that carry a homozygous deletion of the ectoderm enhancer) revealed that FoxE3 expression was undetectable (Dimanlig et al., 2001). This indicated that FoxE3 is located downstream of the placodal phase of Pax6expression in a genetic pathway regulating lens development (Fig. 2).

\section{Sox2}

It is likely that Bmp4 functions in lens induction in a pathway that involves the transcriptional regulator Sox2. Sox2 is an HMG box transcription factor related to the sex-determining factor SRY (Kamachi et al., 1995). Sox2 and family members Sox1 and Sox3 have been implicated in lens development through their expression patterns and through their regulation of crystallin genes (Kamachi et al., 1995; Kamachi et al., 1998). In particular, Sox2 is known to regulate $\delta$-crystallin expression in the chick in a complex with Pax6 (Kamachi etal., 2001). Thus, the observation that Sox2expression 
in the lens lineage is not up-regulated in the usual way in $\mathrm{Bmp} 4$ null embryos suggests the appealing model that Bmp4 stimulates Sox2 expression in preparation for crystallin gene regulation by a Sox2-Pax6 complex (Fig. 3). When combined with the observation that Sox2 is also not up-regulated in the usual way in PaxG ${ }^{\mathrm{Sey} / \mathrm{Sey}}$ embryos (Furuta and Hogan, 1998), we can suggest that Sox2is

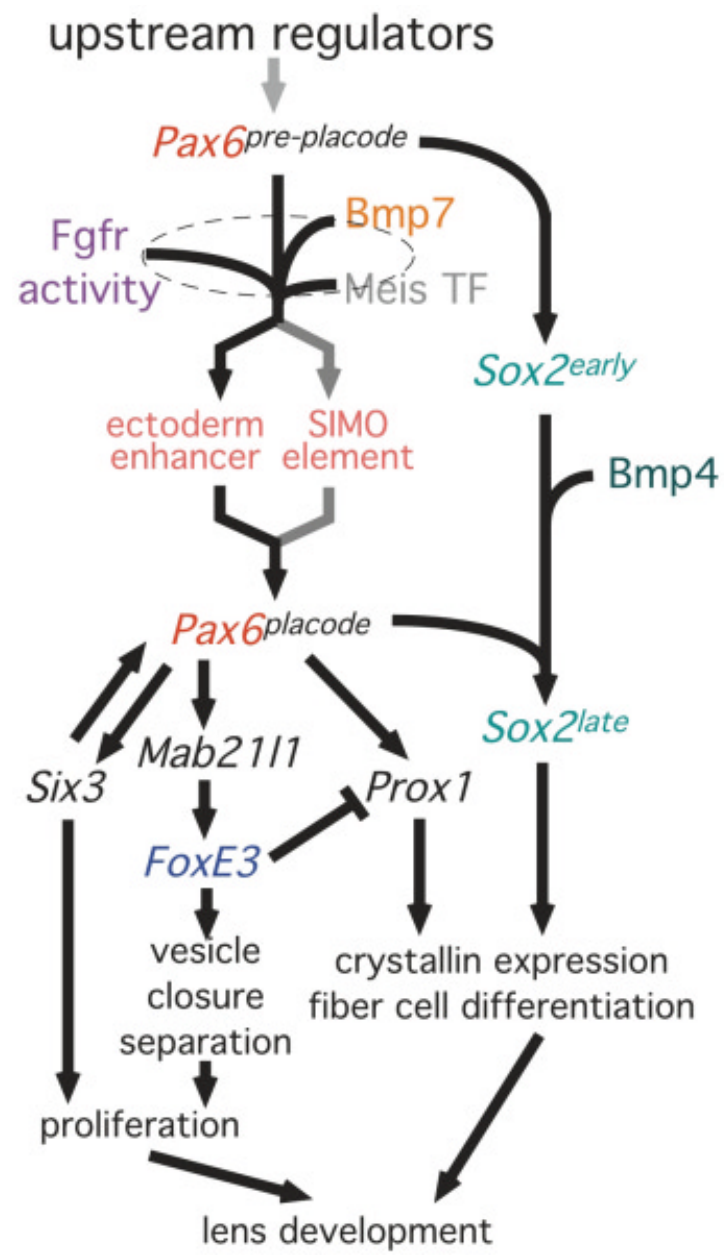

Fig. 3. An expanded model for the genetic pathways regulating lens induction. See Fig. 2 for description of the central elements of this model. Based on the absence of FoxE3 expression in mice carrying a deletion of the Pax6 ectoderm enhancer (Pax6 $6^{\Delta \mathrm{EE} / \Delta \mathrm{EE})}$ FoxE3 is downstream of Pax6 $6^{\text {placode }}$. The similar phenotypes (reduced lens lineage proliferation and lens vesicle closure and separation failure) of the dysgenetic lens (FoxE3) and Pax6 ${ }^{\Delta \mathrm{EE} /}$ $\triangle \mathrm{EE}$ mutant mice argue that FoxE3 is upstream of these cellular responses. Similarly, the loss of FoxE3 expression in Mab2111 mutant mice and the loss

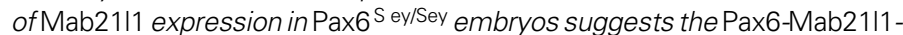
FoxE3 gene order indicated. The homeodomain transcription factor Six3 lies genetically downstream of Pax6 ${ }^{\text {placode }}$ as mice that do not express placodal Pax6 also do not express placodal Six3. This is also true for Prox1. Since FoxE3 ${ }^{\text {dylddyl }}$ mice show an expansion of the Prox 1 expression domain in the lens epithelium, this suggests that FoxE3 normally suppresses Prox 1 at later

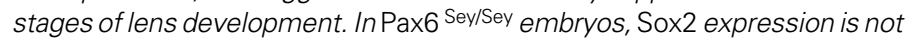
up-regulated in the lens placode suggesting that the late phase of Sox2 expression is dependent on Pax6. Similarly, since Sox2 (but not Pax6) expression is not up-regulated in the lens placode of Bmp4 null mice, Bmp4 signaling likely contributes to the pathway between Sox2 ${ }^{\text {early }}$ and Sox2 $2^{\text {late }}$. downstream of Pax6 pre-placode and participates with Bmp4 in the proposed parallel pathway (Fig. 3). It is likely that currently unpublished work examining the requirement for different Bmp receptors in lens induction will help refine our understanding of Bmp4 involvement in lens induction.

\section{Mab21I1}

The Mab21/1gene from mouse is the orthologue of mab-21from C. elegans(Mariani etal., 1998; Mariani etal., 1999; Yamada etal., 2003). Interestingly, in the worm, mab-21 is in the same genetic pathway as mab-18, the orthologue of vertebrate Pax6 (Zhang and Emmons, 1995). Supporting the idea that Pax6 and Mab21/1might participate in the same developmental processes is the observation that like Pax6, Mab21/1 is expressed in the eye primordium (both presumptive lens and retina) from an early stage (Mariani et al., 1998; Yamada et al., 2003). In particular, Mab21/1 expression is up-regulated at approximately E9.5, thus suggesting it might be responsive to lens induction signals (Yamada et al., 2003).

Recently, generation of a Mab21/1 null mouse has suggested that Mab21/1has an important functional role in lens development. The Mab21/1 null mouse displays lens development defects (in the form of lens placode invagination failure) from E9.5 and this results in a dramatic microophthalmia (Yamada et al., 2003). Examination of Mab21/1expression in Pax $6^{\mathrm{Sey} / \mathrm{Sey}}$ mice indicated a failure of the normal up-regulation at E9.5. This suggested that Mab21/1 was genetically downstream of Pax6. Detection of FoxE3 and Pax6 expression in the Mab21/1 null mutant indicated that Pax6 expression was normal, but that FoxE3 expression was absent at E9.5 (Yamada et al., 2003). Combined, these data suggest that Mab21/1 lies between the placodal phase of Pax6expression and FoxE3in the model for genetic regulation of lens induction (Fig. 2). This analysis suggests that there is a direct analogy between the mab-21,-mab-18 pathway in the worm and the Pax6, Mab21/1 pathway in the mouse (Yamada et al., 2003).

\section{Six3}

Six3 is a member of the six-homeodomain family of which Drosophila sine oculis is the founding member (Cheyette et al., 1994; Serikaku and O'Tousa, 1994). Six3 was first implicated in lens development by its expression pattern. In mice, Six 3 is expressed in the lens epithelium during differentiation stages but is first expressed in the lens placode (Oliver et al., 1995). In Medaka, the expression pattern is somewhat distinct as it is present in the presumptive lens ectoderm but is down-regulated in the lens placode prior to lens differentiation (Loosli et al., 1998). As in the mouse, chick Six 3 is expressed in the presumptive lens ectoderm overlying the optic vesicles but persists in the lens placode and is later localized to the lens epithelium (Bovolenta et al., 1998)

Functional evidence for Six3involvement in lens induction came initially from misexpression studies that resulted in the formation of ectopic lenses in Medaka(Oliver et al., 1996). In contrast to Pax6 induced ectopic lens formation in Xenopus, Six3-induced ectopic lenses appeared to arise as a result of the transformation of the otic vesicle (Oliver etal., 1996). In addition, lineage tracing experiments revealed that Six 3 could direct ectopic lens formation in a cell nonautonomous manner. This led the authors to speculate that Six 3 misexpression may induce a soluble factor that changed the bias of the otic placode towards a lens fate (Oliver et al., 1996). 
There is now evidence to indicate that Six 3 and Pax6mutually activate at the transcriptional level (Ashery-Padan et al., 2000; Goudreau etal., 2002). As mentioned above, lens placode-specific conditional deletion of a floxed allele of Pax6 results in lens development failure (Ashery-Padan et al., 2000). An assessment of marker gene expression in these animals indicates that Six3 expression is lost. Furthermore, it has been shown that an $\alpha$ crystallin promoter-Six3transgene can up-regulate Pax6expression and rescue the lens defects that arise in $\mathrm{Pax}^{\mathrm{lacz} /+}$ mice (Goudreau etal., 2002). When combined with biochemical experiments showing that Six3 binding sites are located in the Pax6 ectoderm enhancer and that Pax 6 binding sites are found in the Six 3 gene (Goudreau et al., 2002), this has suggested that Pax6 and Six3 can mutually transactivate. This information can be incorporated into the genetic model for mouse lens induction (Fig. 3). A direct assessment of the role of Six3 in lens development, and its ability to feedback positively on Pax 6 , will come from conditional deletion of a floxed allele in the lens placode.

\section{Prox1}

Prox 1 is a vertebrate homologue of Drosophila prospero that encodes a divergent homeodomain protein (Tomarev et al., 1998). It is expressed in the presumptive lens and retina in the mouse from an early stage of development. Generation of Prox 1 null allele in the mouse revealed that this transcription factor is essential for the differentiation of lens fiber cells (Wigle et al., 1999). Interestingly, there is now evidence from both Drosophila (Knoblich et al., 1995; Spana and Doe, 1995) and mouse (Duncan et al., 2002) that prospero and Prox1 change their sub-cellular localization at the developmental stage when their activity is critical.

Two analyses allow us to place Prox1 within the model for genetic regulation of lens induction. First, it has been shown that when Pax6 is conditionally deleted from the lens placode, Prox1 expression in this location is lost (Ashery-Padan et al., 2000). Furthermore, In the dysgenetic lens mouse that carries a mutation in FoxE3, Prox1 expression in the lens epithelium is up-regulated. Combined, these data suggest that Prox 1 lies genetically downstream of Pax $6^{\text {placode }}$ and that FoxE3is normally responsible for suppressing Prox1 expression (Fig. 3). It remains to be determined whether these interactions represent many steps or whether there is the possibility of direct transcriptional regulation.

\section{Speculation: is Pax6auto-regulation the result of MAPK- mediated activation?}

Genetic analysis has indicated that Pax6 autoregulates. Specifically, we understand that the placodal phase of Pax6 expression is dependent upon functional Pax6 protein in the head ectoderm ((Grindley et al., 1995); Figs. 2,3). Recent analysis has suggested that this genetic relationship may be the result of a direct regulatory interaction in which Pax6 binds to the EE and activates Pax6(Aota etal., 2003). The evidence for this comes from mobilityshift assays in which, through its paired domain, Pax6 can bind specifically to EE sequences and transfection experiments in which an EE-dependent expression construct is activated by Pax 6 (Aota et al., 2003). However, if Pax $6^{\text {placode }}$ is directly regulated by Pax6 $6^{\text {pre-placode }}$, a problem arises in explaining how the two phases of expression are ever distinct. Two obvious possibilities are that the level of expression distinguishes these two phases or that another input is required. For example, there are no doubt many transcription factors that could function cooperatively with Pax6 at the EE (possibilities are Meis proteins (Zhang et al., 2002), Sox2 or 3 (Aota et al., 2003) or Six3 (Goudreau et al., 2002)).

However, another mechanistic possibility has been raised by analysis indicating that Pax 6 can be activated post-translationally (Mikkola et al., 1999). The transactivation domain of Zebrafish Pax6 has a series of potential phosphorylation sites. Of these, serine $413\left(\mathrm{Ser}^{413}\right)$ is evolutionarily conserved from sea urchin to man. Interestingly, Ser ${ }^{413}$ can be phosphorylated in vitro by the mitogen activated protein kinases (MAPKs), extracellular-signal regulated kinase (ERK) and p38 kinase but not Jun $\mathrm{N}$-terminal kinase (JNK). Mutation of $\operatorname{Ser}^{413}$ to appear similar to a phosphorylated residue enhances the transactivation potential of Pax6. Similarly, mutation of $\mathrm{Ser}^{413}$ to a residue that is the antithesis of a phophorylated side chain limits transactivation (Mikkola et al., 1999). Finally, in NIH3T3 cells, it can be shown that Ser ${ }^{413}$ phosphorylation occurs in response to serum stimulation, a condition that activates the MAP kinases, and that this phosphorylation can by prevented by the MAP kinase inhibitor PD 98059 (Mikkola et al., 1999).

It has clearly been shown that the Fgf signaling pathway is required for lens induction. The Fgf pathway includes, as one of its signaling arms, the Ras-Raf-MAP kinase pathway (Goldfarb, 2001). When combined with the observation that MAP kinases can enhance Pax6 transctivation, we can propose that the placodal phase of Pax6expression is the result of Fgf pathway-MAP kinase mediated activation of Pax6 that is available from Pax6 ${ }^{\text {pre-placode }}$ (Fig. 4). This proposal is entirely consistent with genetic analysis

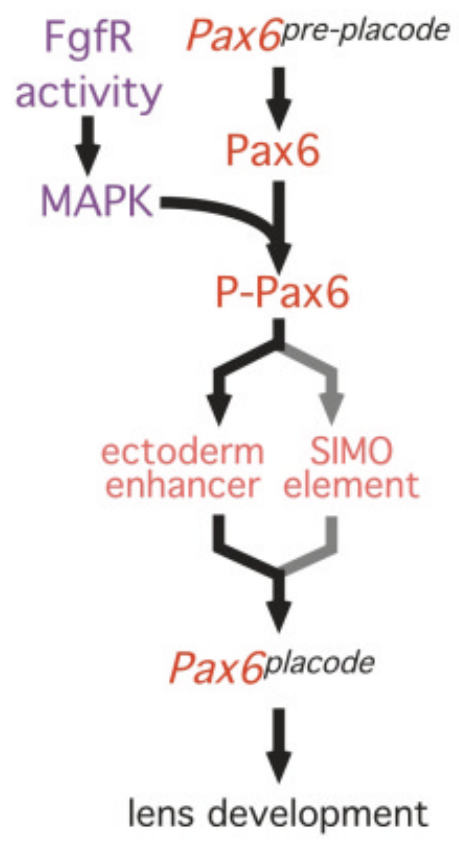

Fig. 4. Is Pax6 phosphorylation a step in lens induction? Phosphorylation of Pax6 by MAP kinase (MAPK) enhances transactivation. Since MAP kinases are downstream of Fgf receptors (FgfR), this raises the possibility that Pax6 phosphorylation is an important step in Pax6 auto-regulation in the lens placode and therefore, lens development. 
suggesting that the Pax6 and Fgf pathways converge upstream of

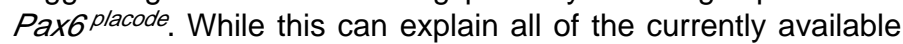
data, there is clearly much experimental work required for a close examination of this potential developmental mechanism.

\section{References}

ALTMANN, C.R., CHOW, R.L., LANG, R.A. and HEMMATI-BRIVANLOU, A. (1997). Lens induction by Pax-6 in Xenopus laevis. Dev Bio/185: 119-23.

AOTA, S., NAKAJIMA, N., SAKAMOTO, R., WATANABE, S., IBARAKI, N. and OKAZAKI, K. (2003). Pax6 autoregulation mediated by direct interaction of Pax6 protein with the head surface ectoderm-specific enhancer of the mouse Pax6 gene. Dev Bio/257: 1-13.

ASHERY-PADAN, R., MARQUARDT, T., ZHOU, X. and GRUSS, P. (2000). Pax6 activity in the lens primordium is required for lens formation and for correct placement of a single retina in the eye. Genes Dev 14: 2701-11.

BESSA, J., GEBELEIN, B., PICHAUD, F., CASARES, F. and MANN, R.S. (2002). Combinatorial control of Drosophila eye development by Eyeless, Homothorax, and Teashirt. Genes Dev 16: 2415-27.

BLIXT, A., MAHLAPUU, M., AITOLA, M., PELTO-HUIKKO, M., ENERBACK, S. and CARLSSON, P. (2000). A forkhead gene, FoxE3, is essential for lens epithelial proliferation and closure of the lens vesicle. Genes Dev 14: 245-54.

BOVOLENTA, P., MALLAMACI, A., PUELLES, L. and BONCINELLI, E. (1998). Expression pattern of cSix 3 , a member of the Six/sine oculis family of transcription factors. Mech Dev70: 201-3.

BROWNELL, I., DIRKSEN, M. and JAMRICH, M. (2000). Forkhead Foxe3 maps to the dysgenetic lens locus and is critical in lens development and differentiation. Genesis 27: 81-93.

BURGLIN, T.R. (1997). Analysis of TALE superclass homeobox genes (MEIS, PBC, KNOX, Iroquois, TGIF) reveals a novel domain conserved between plants and animals. Nucleic Acids Res 25: 4173-80.

CALLAERTS, P., HALDER, G. and GEHRING, W.J. (1997). PAX-6 in development and evolution. Annu Rev Neurosci20: 483-532.

CHEYETTE, B.N., GREEN, P.J., MARTIN, K., GARREN, H., HARTENSTEIN, V. and ZIPURSKY, S.L. (1994). The Drosophila sine oculis locus encodes a homeodomaincontaining protein required for the development of the entire visual system. Neuron 12: 977-96.

CHOW, R.L., ALTMANN, C.R., LANG, R.A. and HEMMATI-BRIVANLOU, A. (1999). Pax6 induces ectopic eyes in a vertebrate. Development 126: 4213-4222.

COLLINSON, J.M., HILL, R.E. and WEST, J.D. (2000). Different roles for Pax6 in the optic vesicle and facial epithelium mediate early morphogenesis of the murine eye. Development 127: 945-56.

CUI, W., TOMAREV, S.I., PIATIGORSKY, J., CHEPELINSKY, A.B. and DUNCAN, M.K. (2004). Mafs, Prox1, and Pax6 can regulate chicken betaB1-crystallin gene expression. J Biol Chem 279: 11088-95.

CZERNY, T., HALDER, G., KLOTER, U., SOUABNI, A., GEHRING, W.J. and BUSSLINGER, M. (1999). twin of eyeless, a second Pax-6 gene of Drosophila, acts upstream of eyeless in the control of eye development. Mol Cel/3: 297-307.

DIMANLIG, P.V., FABER, S.C., AUERBACH, W., MAKARENKOVA, H.P. and LANG, R.A. (2001). The upstream ectoderm enhancer in Pax6 has an important role in lens induction. Development 128: 4415-24.

DUDLEY, A.T., LYONS, K.M. and ROBERTSON, E.J. (1995). A requirement for bone morphogenetic protein-7 during development of the mammalian kidney and eye. Genes Dev 9: 2795-807.

DUDLEY, A.T. and ROBERTSON, E.J. (1997). Overlapping expression domains of bone morphogenetic protein family members potentially account for limited tissue defects in BMP7 deficient embryos. Dev Dyn 208: 349-62.

DUNCAN, M.K., CUI, W., OH, D.J. and TOMAREV, S.I. (2002). Prox1 is differentially localized during lens development. Mech Dev112: 195-8.

FABER, S.C., DIMANLIG, P., MAKARENKOVA, H.P., SHIRKE, S., KO, K. and LANG, R.A. (2001). Fgf receptor signaling plays a role in lens induction. Development 128: 4425-38

FUJIWARA, M., UCHIDA, T., OSUMI-YAMASHITA, N. and ETO, K. (1994). Uchida rat (rSey): a new mutant rat with craniofacial abnormalities resembling those of the mouse Sey mutant. Differentiation 57: 31-8.
FURUTA, Y. and HOGAN, B.L.M. (1998). BMP4 is essential for lens induction in the mouse embryo. Genes Dev12: 3764-3775.

GLASER, T., WALTON, D.S. and MAAS, R.L. (1992). Genomic structure, evolutionary conservation and aniridia mutations in the human PAX6 gene. Nat Genet2: 232-9.

GOLDFARB, M. (2001). Signaling by fibroblast growth factors: the inside story. SCi STKE2001: PE37.

GOUDREAU, G., PETROU, P., RENEKER, L.W., GRAW, J., LOSTER, J. and GRUSS, $P$. (2002). Mutually regulated expression of Pax6 and Six3 and its implications for the Pax6 haploinsufficient lens phenotype. Proc Nat/ Acad Sci USA 99: 8719-24.

GRAINGER, R.M. (1992). Embryonic lens induction: shedding light on vertebrate tissue determination. Trends Genet 8: 349-55.

GRAINGER, R.M. (1996). New perspectives on embryonic lens induction. Cel/ Dev. Biol. 7: 149-155.

GRAINGER, R.M., HENRY, J.J., SAHA, M.S. and SERVETNICK, M. (1992). Recent progress on the mechanisms of embryonic lens formation. Eye 117-22.

GRAINGER, R.M., MANNION, J.E., COOK, T.L.J. and ZYGAR, C.A. (1997). Defining intermediate stages in cell determination: acquisition of a lens-forming bias in head ectoderm during lens determination. Dev Genet20: 246-257.

GRINDLEY, J.C., DAVIDSON, D.R. and HILL, R.E. (1995). The role of Pax-6 in eye and nasal development. Development 121: 1433-42.

GRINDLEY, J.C., HARGETT, L.K., HILL, R.E., ROSS, A. and HOGAN, B.L. (1997). Disruption of PAX6 function in mice homozygous for the Pax6 Sey-1Neu mutation produces abnormalities in the early development and regionalization of the diencephalon. Mech Dev64: 111-26.

HALDER, G., CALLAERTS, P. and GEHRING, W.J. (1995). Induction of ectopic eyes by targeted expression of the eyeless gene in Drosophila. Science267: 1788-1792.

HILL, R.E., FAVOR, J., HOGAN, B.L., TON, C.C., SAUNDERS, G.F., HANSON, I.M., PROSSER, J., JORDAN, T., HASTIE, N.D. and VAN HEYNINGEN, V. (1991) Mouse small eye results from mutations in a paired-like homeobox- containing gene. Nature 354: 522-5.

HISA, T., SPENCE, S.E., RACHEL, R.A., FUJITA, M., NAKAMURA, T., WARD, J.M., DEVOR-HENNEMAN, D.E., SAIKI, Y., KUTSUNA, H., TESSAROLLO, L. et al., (2004). Hematopoietic, angiogenic and eye defects in Meis1 mutant animals. EMBO J23: 450-9

JORDAN, T., HANSON, I., ZALETAYEV, D., HODGSON, S., PROSSER, J., SEAWRIGHT, A., HASTIE, N. and VAN HEYNINGEN, V. (1992). The human PAX6 gene is mutated in two patients with aniridia. Nat Genet 1: 328-32.

KAMACHI, Y., SOCKANATHAN, S., LIU, Q., BREITMAN, M., LOVELL-BADGE, R. and $\mathrm{KONDOH}, \mathrm{H}$. (1995). Involvement of SOX proteins in lens-specific activation of crystallin genes. EMBO J14: 3510-9.

KAMACHI, Y., UCHIKAWA, M., COLLIGNON, J., LOVELL-BADGE, R. and KONDOH, H. (1998). Involvement of Sox1, 2 and 3 in the early and subsequent molecular events of lens induction. Development 125: 2521-32.

KAMACHI, Y., UCHIKAWA, M., TANOUCHI, A., SEKIDO, R. and KONDOH, H. (2001). Pax6 and SOX2 form a co-DNA-binding partner complex that regulates initiation of lens development. Genes Dev 15: 1272-86.

KAMMANDEL, B., CHOWDHURY, K., STOYKOVA, A., APARICIO, S., BRENNER, S. and GRUSS, P. (1999). Distinct cis-essential modules direct the time-space pattern of the Pax6 gene activity. Dev Bio/205: 79-97.

KLEINJAN, D.A., SEAWRIGHT, A., SCHEDL, A., QUINLAN, R.A., DANES, S. and VAN HEYNINGEN, V. (2001). Aniridia-associated translocations, DNase hypersensitivity, sequence comparison and transgenic analysis redefine the functional domain of PAX6. Hum Mol Genet 10: 2049-59.

KNOBLICH, J.A., JAN, L.Y. and JAN, Y.N. (1995). Asymmetric segregation of Numb and Prospero during cell division. Nature 377: 624-7.

LANG, R.A. and MCAVOY, J.W. (2003). Growth factors in lens development. In Development of the ocular lens, (ed. M. L. Robinson and F. J. Lovicu).

LOOSLI, F., KOSTER, R., CARL, M., KRONE, A. and WITTBRODT, J. (1998). Six3, a medaka homologue of the Drosophila homeobox gene sine oculis is expressed in the anterior embryonic shield and the developing eye. Mech Dev 74: 159-64.

LOVICU, F.J. and OVERBEEK, P.A. (1998). Overlapping effects of different members of the FGF family on lens fiber differentiation in transgenic mice. Development 125 : 3365-77.

LUO, G., HOFMANN, C., BRONCKERS, A.L., SOHOCKI, M., BRADLEY, A. and KARSENTY, G. (1995). BMP-7 is an inducer of nephrogenesis, and is also required for eye development and skeletal patterning. Genes Dev9: 2808-20. 
MARIANI, M., BALDESSARI, D., FRANCISCONI, S., VIGGIANO, L., ROCCHI, M., ZAPPAVIGNA, V., MALGARETTI, N. and CONSALEZ, G.G. (1999). Two murine and human homologs of mab-21, a cell fate determination gene involved in Caenorhabditis elegans neural development. Hum Mol Genet 8: 2397-406.

MARIANI, M., CORRADI, A., BALDESSARI, D., MALGARETTI, N., POZZOLI, O., FESCE, R., MARTINEZ, S., BONCINELLI, E. and CONSALEZ, G.G. (1998). Mab21, the mouse homolog of a $C$. elegans cell-fate specification gene, participates in cerebellar, midbrain and eye development. Mech Dev79: 131-5.

MCAVOY, J.W. (1980). Cytoplasmic processes interconnect lens placode and optic vesicle during eye morphogenesis. Experimental Eye Research 31: 527-34.

MCAVOY, J.W., CHAMBERLAIN, C.G., DE IONGH, R.U., HALES, A.M. and LOVICU, F.J. (1999). Lens development. Eye 13: 425-37.

MCAVOY, J.W., CHAMBERLAIN, C.G., DE IONGH, R.U., RICHARDSON, N.A. and LOVICU, F.J. (1991). The role of fibroblast growth factor in eye lens development. Ann. N. Y. Acad. Sci. 638: 256-74.

MCWHIRTER, J.R., GOULDING, M., WEINER, J.A., CHUN, J. and MURRE, C. (1997). A novel fibroblast growth factor gene expressed in the developing nervous system is a downstream target of the chimeric homeodomain oncoprotein E2A-Pbx1. Development 124: 3221-32.

MENCL, E. (1903). Ein fall von beiderseitiger augenlinsenausbildung wahrend der abwesenheit von augenblasen. Arch. EntwMech. Org. 16: 328-339.

MIKKOLA, I., BRUUN, J.A., BJORKOY, G., HOLM, T. and JOHANSEN, T. (1999). Phosphorylation of the transactivation domain of Pax6 by extracellular signalregulated kinase and p38 mitogen-activated protein kinase. J Biol Chem 274: 15115-26.

NORNES, S., CLARKSON, M., MIKKOLA, I., PEDERSEN, M., BARDSLEY, A., MARTINEZ, J.P., KRAUSS, S. and JOHANSEN, T. (1998). Zebrafish contains two pax6 genes involved in eye development. Mech Dev77: 185-96.

OLIVER, G., LOOSLI, F., KOESTER, R., WITTBRODT, J. and GRUSS, P. (1996). Ectopic lens induction in fish in response to the murine homeobox gene Six3. Mech. Dev. 60: 233-239.

OLIVER, G., MAILHOS, A., WEHR, R., COPELAND, N.G., JENKINS, N.A. and GRUSS, P. (1995). Six3, a murine homologue of the sine oculis gene, demarcates the most anterior border of the developing neural plate and is expressed during eye development. Development 121: 4045-55.

PIATIGORSKY, J. (1998). Multifunctional lens crystallins and corneal enzymes. More than meets the eye. Ann $N$ Y Acad Sci842: 7-15.

QUINN, J.C., WEST, J.D. and HILL, R.E. (1996). Multiple functions for Pax6 in mouse eye and nasal development. Genes Dev 10: 435-46.

QUIRING, R., WALLDORF, U., KLOTER, U. and GEHRING, W.J. (1994). Homology of the eyeless gene of Drosophila to the Small eye gene in mice and Aniridia in humans. Science 265: 785-9.

SEMINA, E.V., BROWNELL, I., MINTZ-HITTNER, H.A., MURRAY, J.C. and JAMRICH, M. (2001). Mutations in the human forkhead transcription factor FOXE3 associated with anterior segment ocular dysgenesis and cataracts. Hum Mo/ Genet 10: 231-6.

SERIKAKU, M.A. and O'TOUSA, J.E. (1994). sine oculis is a homeobox gene required for Drosophila visual system development. Genetics 138: 1137-50.
SERVETNICK, M. and GRAINGER, R.M. (1991). Changes in nerual and lens competence in Xenopus ectoderm: evidence for an autonomous developmental timer. Development 112: 177-188.

SERVETNICK, M.D., COOK, T., JR. and GRAINGER, R.M. (1996). Lens induction in axolotls: comparison with inductive signaling mechanisms in Xenopus laevis. Int J Dev Biol40: 755-61.

SPANA, E.P. and DOE, C.Q. (1995). The prospero transcription factor is asymmetrically localized to the cell cortex during neuroblast mitosis in Drosophila. Development 121: 3187-95.

SPEMANN, H. (1901). Uber Correlationen in der Entwickelung des Auges. Verh Anat Ges 15: 61-79.

SULLIVAN, C.H., BRAUNSTEIN, L., HAZARD-LEONARDS, R.M., HOLEN, A.L. SAMAHA, F., STEPHENS, L. and GRAINGER, R.M. (2004). A re-examination of lens induction in chicken embryos: in vitro studies of early tissue interactions. Int. J. Dev. Biol. 48: 771-782.

TOMAREV, S.I., ZINOVIEVA, R.D., CHANG, B. and HAWES, N.L. (1998). Characterization of the mouse Prox1 gene. Biochem Biophys Res Commun 248: 684-9.

TREISMAN, J. and LANG, R. (2002). Development and evolution of the eye: Fondation des Treilles, September, 2001. Mech Dev 112: 3-8.

VOGEL-HOPKER, A., MOMOSE, T., ROHRER, H., YASUDA, K., ISHIHARA, L. and RAPAPORT, D.H. (2000). Multiple functions of fibroblast growth factor-8 (FGF-8) in chick eye development. Mech Dev 94: 25-36.

WAWERSIK, S., PURCELL, P., RAUCHMAN, M., DUDLEY, A.T., ROBERTSON, E.J. and MAAS, R. (1999). BMP7 Acts in Murine Lens Placode Development. Dev Bio/207: 176-188.

WEAVER, M. and HOGAN, B. (2001). Powerful ideas driven by simple tools: lessons from experimental embryology. Nat Cell Bio/3: E165-7.

WIGLE, J.T., CHOWDHURY, K., GRUSS, P. and OLIVER, G. (1999). Prox1 function is crucial for mouse lens-fibre elongation. Nat Genet 21: 318-22.

WILLIAMS, S.C., ALTMANN, C.R., CHOW, R.L., HEMMATI-BRIVANLOU, A. and LANG, R.A. (1998). A highly conserved lens transcriptional control element from the Pax-6 gene. Mech Dev 73: 225-9.

XU, P.X., ZHANG, X., HEANEY, S., YOON, A., MICHELSON, A.M. and MAAS, R.L. (1999). Regulation of Pax6 expression is conserved between mice and flies. Development 126: 383-95.

YAMADA, R., MIZUTANI-KOSEKI, Y., HASEGAWA, T., OSUMI, N., KOSEKI, H. and TAKAHASHI, N. (2003). Cell-autonomous involvement of Mab21l1 is essential for lens placode development. Development 130: 1759-70.

ZHANG, X., FRIEDMAN, A., HEANEY, S., PURCELL, P. and MAAS, R.L. (2002). Meis homeoproteins directly regulate Pax6 during vertebrate lens morphogenesis. Genes Dev 16: 2097-107.

ZHANG, Y. and EMMONS, S.W. (1995). Specification of sense-organ identity by a Caenorhabditis elegans Pax-6 homologue. Nature 377: 55-9.

ZUBER, M.E., GESTRI, G., VICZIAN, A.S., BARSACCHI, G. and HARRIS, W.A. (2003). Specification of the vertebrate eye by a network of eye field transcription factors. Development 130: 5155-67. 